\title{
Additions to the species of Dasyhelea KIEFFER, 1911 (Diptera: Ceratopogonidae) from West Bengal, India
}

\author{
SHUBHRANIL BRAHMA, NILADRI HAZRA* \\ Entomology Research Unit, Department of Zoology, The University of Burdwan, \\ Purba Bardhaman, 713104, India
}

\begin{abstract}
Adult males of three new species, Dasyhelea (Prokempia) barbistyla, Dasyhelea (Pseudoculicoides) pseudohama and D. (Sebessia) scalpra are described from India. The Palaearctic species Dasyhelea (Dasyhelea) pallidiventrisis recorded for the first time from India. Dasyhelea (Ps.) deemingi BOORMAN \& HARTEN, 2002 is revised, Dasyhelea (Ps.) acuta BRAHMA, SAHA \& HAZRA, 2016 is deemed a junior synonym of Dasyhelea similinigrina NAVAI, 1994, and a key to the Indian species of the subgenera Dasyhelea, Prokempia, Pseudoculicoides and Sebessia is provided.
\end{abstract}

KEY WORDS: Dasyhelea, Pseudoculicoides, Prokempia, Sebessia, taxonomy, new species, new record, new synonym, India.

\section{INTRODUCTION}

The genus Dasyhelea KIEFFER, 1911 is a speciose and complex group of Ceratopogonidae with a diverse morphology and biology. The genus is the third most abundant group after Culicoides LAtreIlle, 1809 and Forcipomyia MeIGen, 1818 (Borkent 2016). The genus Dasyhelea is widely distributed and recorded in all biogeographical regions except Antarctica (GROGAN \& WIENERS 2006). To date, more than 624 species have been described worldwide. With regard to ranking the diversity of the genus Dasyhelea among the different biogeographical regions, the Palaearctic Region comes first with about 209 species (BORKENT 2016). Approximately 136 species of Dasyhelea have so far been

\footnotetext{
* Corresponding author: hazra.niladri@gmail.com
} 
described from the Oriental Region, the second highest number among the various biogeographical regions (BORKENT 2016). Of these, around 84 species ( $60 \%$ of the total number of Oriental species) have been described from China; only 23 species have been described solely from India (BORKENT 2016, BRAHMA et al. 2016). The Australasian region can boast just 9 species (BORKENT 2016). In India, studies of the genus Dasyhelea are still in their infancy.

In this paper we describe three new species from three separate subgenera, namely, Prokempia KiefFer, 1915, Pseudoculicoides Malloch, 1915 and Sebessia Remm, 1979, of the genus Dasyhelea. In addition, detailed illustrations and a review of Dasyhelea (Pseudoculicoides) deemingi BOORMAN \& HARTEN, 2002 are provided. Dasyhelea (Dasyhelea) pallidiventris GOETGHEBUER, 1931, described earlier from the Palaearctic region, has also been recorded from India. Dasyhelea (Ps.) acuta BRAHMA, SAHA \& HAZRA, 2016 is given as a junior synonym of D. Similinigrina NAVAI, 1994. Two illustrations of D. (Ps.) comosa BRAHMA, SAHA \& HAZRA, 2016 are given. A key to the Indian species of the subgenera Dasyhelea s. str., Prokempia KIEFFER, 1913, Pseudoculicoides MaLloch, 1915 and Sebessia REMm, 1979 are also provided.

\section{MATERIAL AND METHODS}

The adults were collected at various sites in West Bengal. Both open type and fabricated UV light traps were used during collection. In the case of the open light trap, a $23 \mathrm{~W}$ white bulb was used along with a small amount of glacial acetic acid in water as attractant. The UV light trap contained an $8 \mathrm{~W}$ UV lamp, a suction fan and a container with $70 \%$ ethanol mounted beneath the fan. Specimens were taken to the laboratory and preserved in $80 \%$ ethanol, thereafter mounted on slides in accordance with the phenol-balsam technique (WIRTH \& MARSTON 1968). Measurements were made in micrometres $(\mu \mathrm{m})$ with ranges followed by mean values in parentheses when there were more than two specimens. Whole body lengths, wing lengths and widths are given in millimetres $(\mathrm{mm})$. The species were identified to the subgeneric level after DOMINIAK (2012). The terminology follows BROWN et al. (2009). The photographs were taken with an MLX-TR Magnus trinocular compound microscope (Magnus Analytics, New Delhi) and WinJoe X86 camera with software (Manufacturer- Future Optics Sci. \& Tech. Co. Ltd, Hangzhou, China).

The type specimens are at present housed in the Entomological collections of the Department of Zoology, The University of Burdwan (India), and will be deposited in the National Zoological Collections (NZCI), Kolkata in due course. 
Abbreviations of morphological terms used in the text and/or figures: AR - Antennal ratio, CR - Costal ratio, PR - Palpal ratio, WL - Wing length, WW - Wing width, $\mathrm{SCh}-$ Sensilla Chaetica.

\section{RESULTS AND DISCUSSION}

Genus Dasyhelea KIEFFER, 1911

Subgenus Prokempia KIEFFER, 1913

Dasyhelea (Prokempia) barbistyla sp. n.

(Figs 1a-n)

\section{Material examined}

Holotype male, labelled 'Dasyhelea (Prokempia) barbistyla BRAHMA \& HAZRA, India,

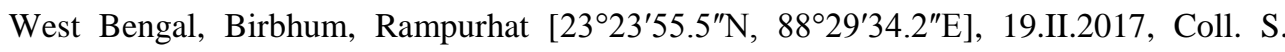
ChATTERJEE'. Paratypes 2 males, India, West Bengal, Hooghly, Dwarbasini [22 $59^{\prime} 33.5^{\prime \prime} \mathrm{N}$, 88¹3'25.3"E], 25.VI.2017, Coll. K.K. Sow.

\section{Diagnosis}

Dasyhelea (Prokempia) barbistyla sp. n. can be distinguished by: triangular projection at inner laterads of gonocoxite; bearded proximal region of gonostylus; bifurcated posterolateral arms of aedeagus; very long, tubular, ventrally curved posteromedian projection of paramere; presence of sensilla basiconica in flagellomeres X-XIII.

Male ( $\mathrm{n}=3)$

Total length. 1.57-1.71 (1.71) $\mathrm{mm}$.

Head. Brown in colour. Eyes pubescent, separated by a distance of 1 ommatidium. Flagellomeres (Fig. 1a) sculptured; length ratio of flagellomeres (I-XIII): 9.00-10.00 (10.00): 7.50-8.00 (8.00): 4.50-5.00 (5.00): 5.50-6.00 (6.00): 5.00 (5.00): 6.00 (6.00): 6.00 (6.00): 6.00 (6.00): 5.50-7.00 (7.00): 13.00-15.00 (15.00): 15.00 (15.00): 13.00-13.50 (13.50): 19.00-21.00 (21.00); AR 1.35-1.38 (1.37); bases of SCh large, circular and prominent; sensilla basiconica present in flagellomeres X-XIII: 2: 2: 2: 3. Frontal sclerite 40.00-42.00 (42.00) $\mu \mathrm{m}$ long, 22.50-24.00 (24.00) $\mu \mathrm{m}$ wide, roughly heart-shaped (Fig.1b). Clypeus with 3 pairs of setae. Maxillary palpal (Fig. 1c) segments (I-V): 3.00 (3.00): 4.50-5.00 (5.00): 7.00 (7.00): 5.00 (5.00): 7.50-8.00 (8.00); PR 1.30-1.40 (1.40) with 4 setae. 

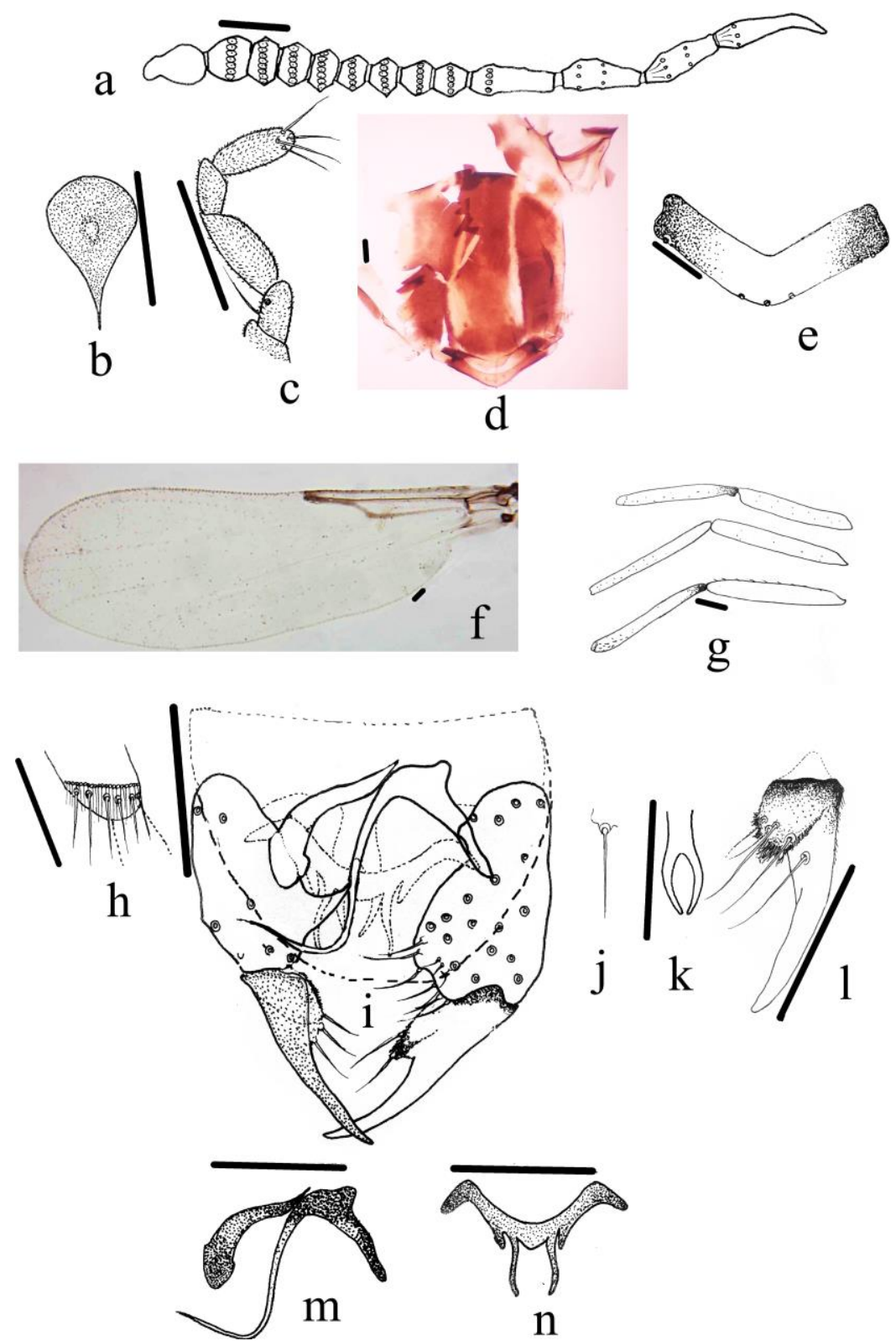

Fig. 1. Adult male of Dasyhelea (Prokempia) barbistyla sp. n.: a, Flagellomeres; b, Frontal sclerite; c, Maxillary palp; d, Thorax; e, Scutellum; f, Wing; g, Femora and tibiae of fore, mid and hind legs; h, Hind tibial comb; i, Genitalia showing left dorsal and right ventral view; j, Apicolateral process; k, Pincer-like median process of sternum 9; 1, Enlarged view of gonostylus; m, Paramere; n, Aedeagus. Scale bar: 0.05 mm. 
Thorax. Reddish brown in colour and with pale spots as in figure 1d. Scutellum (Fig.1e) pale, heavily sclerotised at both laterals. 5 scutellars, 3 of which situated in mid-section, the others at the extremities.

Wing (Fig. 1f). WL 0.70-0.76 (0.76) $\mathrm{mm}$ and WW 0.25-0.28 (0.28) mm. Macrotrichia very sparse on wing surface, venation faint; CR 0.34-0.37 (0.37).

Legs (Fig. 1g). Pale brown in colour. Hind tibial comb (Fig. 1h) with 6 spines. Tarsomeres I-V of fore leg pale, tarsomeres I-IV of other legs pale, tarsomere V somewhat darker.

Abdomen. Tergites dark brown in colour.

Genitalia (Fig. 1i). Tergite 9 dark brown in colour with 11-12 setae, extended beyond gonocoxite-gonostylus junction, cercus with two prominent setae, apicolateral processes (Fig. 1j) small with distinct seta of 11.50-12.50 (12.00) $\mu \mathrm{m}$ long. Sternite 9 pincer-shaped, surpassing basal arch of aedeagus (Fig. 1k). Gonocoxite stout, 52.00-52.50 (52.50) $\mu \mathrm{m}$ long and 29.00-30.00 (30.00) $\mu \mathrm{m}$ wide, a triangular pointed projection at about distal onethird region facing inner laterad. Gonostylus (Fig. 11) $45 \mu \mathrm{m}$ long, 8.00-9.00 (9.00) $\mu \mathrm{m}$ wide at base and $3.00(3.00) \mu \mathrm{m}$ wide at apex, latter blunt; base bearing a constriction with a prominent seta. Paramere (Fig. $1 \mathrm{~m}$ ) highly asymmetrical; basal arms highly sclerotised, directed posterolaterad, left arm stout, 29.00-30.00 (30.00) $\mu \mathrm{m}$ long, right arm 97.00105.00 (105.00) $\mu \mathrm{m}$ long; posteromedian projection very long, tubular, curved ventrally and tip pointed. Aedeagus (Fig. 1n) 26.00-27.00 (27.00) $\mu \mathrm{m}$ long; basal arch 28.50-30.0 (30.0) $\mu \mathrm{m}$ long; basal arms stout, highly sclerotised, directed posterolaterad, 11.50-12.00 (12.00) $\mu \mathrm{m}$ long, extended up to half width of gonocoxite ventrally; posterolateral arms slender, heavily sclerotised with $18.00-19.00(18.50) \mu \mathrm{m}$, each one with lateral bifurcation.

\section{Female}

Unknown.

\section{Immature}

Unknown.

\section{Remarks}

This species resembles Dasyhelea flava CARTER, INGRAM \& MACFIE, 1921 in the overall shape of the paramere, aedeagus and pincer, but the gonocoxite is somewhat elongated and the gonostylus is not bifurcated in D. (Pr.) barbistyla sp. n. Dasyhelea bilobata KIEFFER, 1915 has a more or less similar type of bifurcated aedeagus but the gonostylus is broad, the posteromedian projection of the paramere is not slender and the apicolateral processes are finger-like. Dasyhelea hanoiensis YU, 2003 shares similarities with the new species in the roughly similar type of aedeagus with bifurcated posterolateral 
arm and slender, elongated posteromedian projection of paramere, but the gonostylus is more or less equally thickened from base to apex, the apicolateral processes are stout and very large, and the terminal flagellomere has a distinct apical projection. The posteromedian projection of the paramere, bifurcated posterolateral arms of the aedeagus and the bearded proximal region of the gonostylus of $D$. (Pr.) taiwana TokUnAGA, 1940 resemble those of the new species, but the shape of the pincer, gonocoxite and gonostylus differ markedly. The genitalia of $D$. barbistyla sp. n. resemble those of $D$. (Pr.) flaviformis CARTER, INGRAM \& MACFIE, 1921, in that they have a similar type of gonocoxite, a roughly similar paramere and apicolateral processes, but in the case of $D$. flaviformis, the presence of a prominent notch at the base of the gonostylus, the projection of the basal arm of the aedeagus and the shape of the pincer on the ninth sternum differ markedly from each other. However, the combination of characters provided in this diagnosis validates $D$. (Prokempia) barbistyla sp. n. as a new member of this subgenus.

\section{Etymology}

The name, 'barbistyla', refers to the Latinised version of the bearded basal region of the gonostylus.

\section{Distribution}

India (West Bengal, altitude: 20-40 m).

\section{Dasyhelea (Pseudoculicoides) pseudohama sp. $\mathbf{n}$.}

(Figs 2a-m)

\section{Material examined}

Holotype male, labelled 'Dasyhelea (Pseudoculicoides) pseudohama BRAHMA \& HAZRA, India, West Bengal, Jalpaiguri, Maynaguri [26³4'13.9"N, 8849'58"E], 11.VII.2016, Coll. S. BRAHMA'. Paratypes: 2 males, West Bengal, Birbhum, Ilambazar [233' $\left.47.9^{\prime \prime} \mathrm{N}, 8^{\circ} 36^{\prime} 22.5^{\prime \prime} \mathrm{E}\right]$, 08.X.2017, data as before, 1 male, West Bengal,

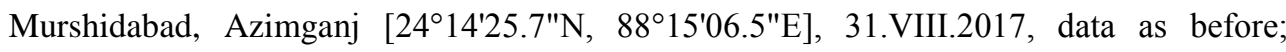
1 male, West Bengal, North 24 Parganas, Khardaha [22 $\left.43^{\prime} 20.7^{\prime \prime N}, 88^{\circ} 23^{\prime} 19.0^{\prime \prime} \mathrm{E}\right]$, 24.XI.2017, Coll. T. MUKHERJEE.

\section{Diagnosis}

Dasyhelea (Ps.) pseudohama sp. n. may be distinguished by the broad aedeagus with bracket-shaped basal arms, the tongue-like appearance of the posteromedian projection of 

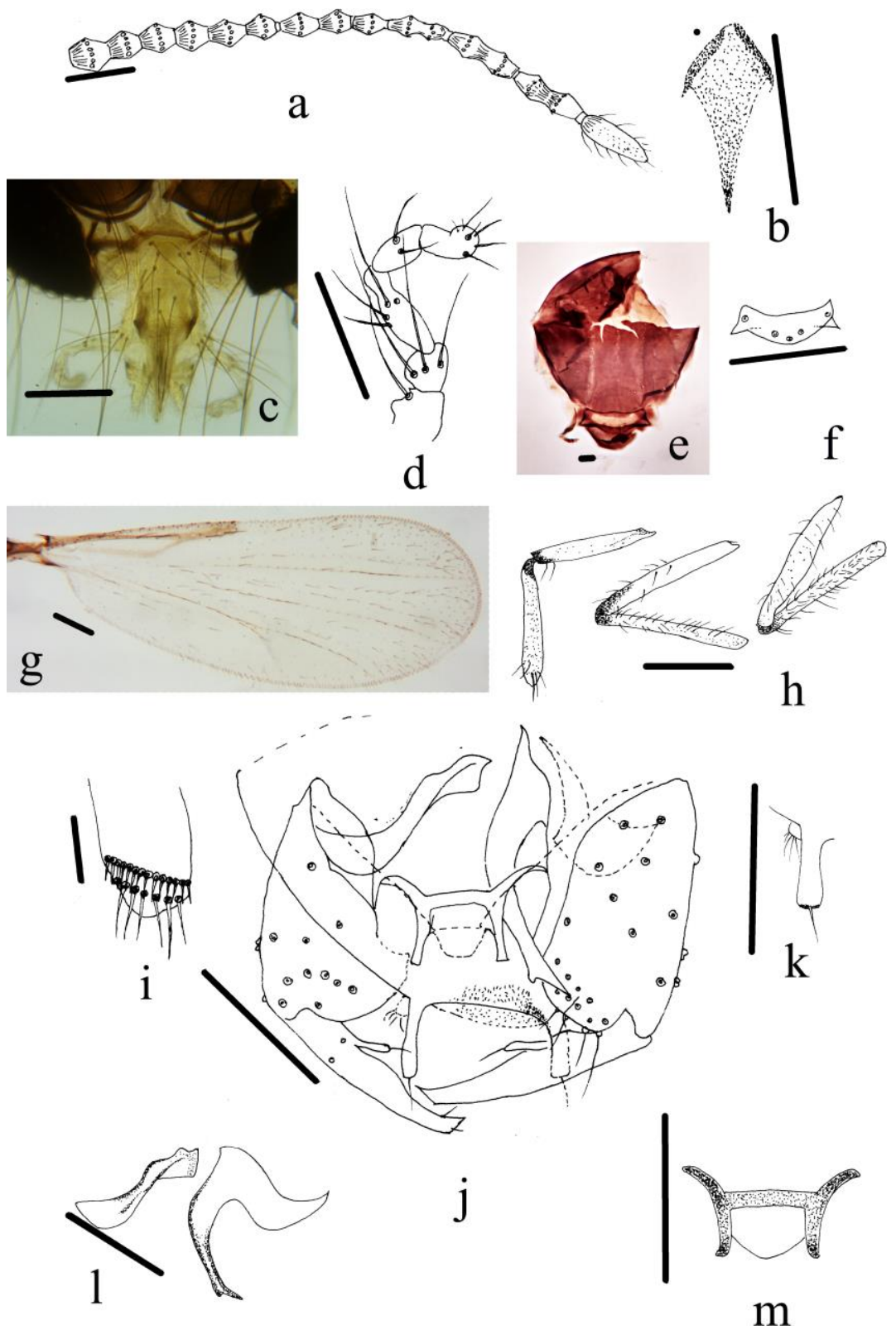

Fig. 2. Adult male of Dasyhelea (Pseudoculicoides) pseudohama sp. n.: a, Flagellomeres; b, Frontal sclerite; c, Head showing the clypeus; d, Maxillary palp; e, Thorax; f, Scutellum; g, Wing; h, Femora and tibiae of fore, mid and hind legs; i, Hind tibial comb; j, Genitalia showing left dorsal and right ventral view; $\mathrm{k}$, Apicolateral process; 1, Paramere; $\mathrm{m}$, Aedeagus. Scale bar: $0.05 \mathrm{~mm}$. 
the aedeagus, the single distinct seta at the apex of the inner gonostylus, two prominent setae at the base of the outer gonostylus, and the "heel"-like appearance of the tip of the posteromedial arm of the paramere of the male genitalia.

\section{Male (n = 5)}

Total length. 1.16-1.20 (1.18) $\mathrm{mm}$.

Head. Blackish brown. Eyes pubescent, continuous, separated by a distance of one ommatidium. Flagellomeres (Fig. 2a) sculptured; length ratio of flagellomeres (I-XIII): 9.50-10.00 (10.00): 9.00-9.50 (9.00): 7.00-7.50 (7.00): 6.00-6.50 (6.50): 6.50-7.00 (6.5.): 6.00-6.50 (6.50): 7.00 (7.00): 7.00-7.50 (7.00): 7.00-7.50 (7.00): 11.50-12.00 (12.00): 14.00-15.50 (15.00): 12.50-14.00 (14.00): 11.00-13.00 (13.00); AR 0.90-10.00 (1.00). Frontal sclerite (Fig. 2b) 36.00-39.00 (39.00) $\mu \mathrm{m}$ long, 19.50-21.00 (21.00) $\mu \mathrm{m}$ wide, rhomboid. Clypeus pale brown (Fig. 2c) with 4 pairs of setae. Maxillary palpal (Fig. 2d) segments I, II, III and IV with 1, 4, 2 and 4 setae respectively, V with 6 thin setae apically; length ratio of palp segments (I-V): 4.00-5.00 (5.00): 5.00 (5.00): 8.50-10.00 (10.00): 4.00-5.50 (5.00): 5.00-6.00 (6.00); PR 3.30.

Thorax (Fig. 2e). Cyan brown to dark brown in colour. Scutellum (Fig. 2f) with 5 setae, having distinct projections at laterads.

Wing (Fig. 2g). WL 0.59-0.64 (0.62), WW 0.24-0.26 (0.24), CR 0.40-0.45 (0.43). Haltere white.

Legs (Fig. 2h). Fore leg pale with faint brown patch apically in femur, basally in tibia, apex of mid femur with a dark brown streak and a dark brown patch at base of tibia, hind tibia with dark brown base; hind tibial comb (Fig. 2i) with 6 spines, second from extreme right longest and stout. Tarsomeres I-IV pale, tarsomere V slightly darker.

Abdomen. Posterior tergites darker than anterior ones.

Genitalia (Fig. 2j). Tergite 9 broad, extended up to gonocoxite-gonostylus junction, cercus with 4 setae; apicolateral process (Fig. 2k) 15.00-18.00 (16.00) $\mu \mathrm{m}$ long, $3 \mu \mathrm{m}$ wide at base, $4.50 \mu \mathrm{m}$ wide apex bearing $7.50 \mu \mathrm{m}$ long seta, region between processes studded with minute setae. Sternite 9 extended upto middle of posteromedial projection of aedeagus, $0.36 \times$ length of greatest width. Gonocoxite broad, stout, $51.00-54.00(52.00) \mu \mathrm{m}$ long, 21.00-27.00 (25.00) $\mu \mathrm{m}$ wide at apex, 33.00-36.00 (36.00) $\mu \mathrm{m}$ wide at base. Gonostylus 42.00-51.00 (47.00) $\mu \mathrm{m}$ long, 6.00 (6.00) $\mu \mathrm{m}$ wide at base and $3.00(3.00) \mu \mathrm{m}$ wide at apex, bifurcated with two prominent setae at one-third length from base of outer gonostylus and inner gonostylus 9.00-13.50 (11.50) $\mu \mathrm{m}$ long with a distinct seta of 6.00 (6.00) $\mu \mathrm{m}$ long at tip. Paramere (Fig. 2l) asymmetrical; basal arms sclerotised, stout, left one twisted, 39.00-45.00 (42.00) $\mu \mathrm{m}$ and right one 48.00-54.00 (52.00) $\mu \mathrm{m}$ long, broad; posteromedian projection terminating in a sharp tip with a lateral knob. Aedeagus (Fig. $2 \mathrm{~m}$ ) $30.00(30.00) \mu \mathrm{m}$ wide, $12.00-15.00$ (14.00) $\mu \mathrm{m}$ long, heavily sclerotised, basal arms 
directed laterad; posterolateral arms sclerotised, subparallel, recurved slightly, posteromedian projection inverted dome-shaped.

\section{Female}

Unknown.

\section{Immature}

Unknown.

\section{Remarks}

This new species looks like D. hama YU in YU et al. 2005 in the bifurcated gonostylus, roughly similar shaped paramere and the large apicolateral process, but the broader gonocoxite, broadly tipped outer gonostylus and long posterolateral arms of aedeagus of $D$. pseudohama sp. n. are contrasting. Dasyhelea arrhena WANG, GUAN \& YU, 2015 comes closer to the present species in its roughly similar shaped frontal sclerite, sculptured flagellomeres IX-XI and asymmetrical paramere, but differs markedly in the shape of the larger right half of the paramere, clypeal structure and number of setae, structures of apicolateral process and maxillary palp segments. Dasyhelea comosa BRAHMA, SAHA \& HAZRA, 2016 shows affinities with the new species in the asymmetrical paramere, the more or less identical shape of the gonocoxite and outer gonostylus, but in the case of $D$. pseudohama sp. $\mathrm{n}$. the tip of the apicolateral process is knobbed, the inner gonostylus tip is not bifurcated, and the posterolateral arms of the aedeagus differ greatly. Dasyhelea uncinata DENG \& YU in YU et al. (2005) shares similarities in the bifurcated gonostylus and asymmetrical paramere with the present species, but there are dissimilarities in the shapes of the gonocoxite, gonostylus, paramere, aedeagus and apicolateral process. Dasyhelea pseudohama sp. $\mathrm{n}$. differs from $D$. uncinata in not having a mesoventral hook on the gonocoxite, a more or less straight outer margin of outer gonostylus, a broad basal arm in the right half of the paramere, and long, simple posterolateral arms in the aedeagus. Dasyhelea jingboi $\mathrm{YU}$ in $\mathrm{YU}$ et al. (2005) is very similar to D. pseudohama sp. $\mathrm{n}$. in the overall similarly shaped paramere and aedeagus, but in D. pseudohama the apex of the gonocoxite is broader, the gonostylus is bifurcated and the posterolateral arms of the aedeagus are long. Nevertheless, the combination of characters stated in the diagnosis justifies $D$. (Ps.) pseudohama sp. n. as a new member of this genus.

\section{Etymology}

The species name, "pseudohama" refers to the similarity with its congener Dasyhelea hama $\mathrm{YU}$ in $\mathrm{YU}$ et al. 2005 in its paramere and aedeagus. 


\section{Distribution}

India (West Bengal, altitude: 15-84 m).

\section{Subgenus Sebessia REMM, 1979 \\ Dasyhelea (Sebessia) scalpra sp. n.}

(Figs 3a-l)

\section{Material examined}

Holotype: male, labelled 'Dasyhelea (Sebessia) scalpra BRAHMA \& HAZRA, India,

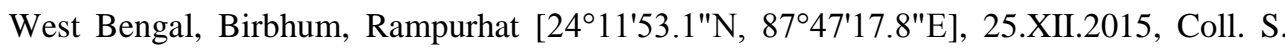
CHATTERJEE'. Paratypes 2 males, data as before.

\section{Diagnosis}

Dasyhelea (Ps.) scalpra sp. $\mathrm{n}$. is unique in that it has the following combination of characters: gonostylus arched semi-circularly with three small setae subapically, cercus with five prominent setae, indistinct apicolateral processes, and symmetrical paramere with slender posteromedian projection.

Male $(\mathrm{n}=3)$

Total length. 1.2-1.25 (1.23) $\mathrm{mm}$.

Head. Light brown in colour. Eyes pubescent, more or less fused, separated by a distance of half an ommatidium. Flagellomeres (Fig. 3a) sculptured; length ratio of flagellomeres (I-XIII): 10.00-11.00 (10.50): 6.00 (6.00): 6.50 (6.50): 6.00-7.00 (6.50): 6.50-7.00 (7.00): 7.00 (7.00): 7.00(7): 7.00 (7.00): 7.00 (7.00): 11.00-12.00 (11.50): 13.00-14.00 (14.00): 12.00 (12.00): 13.00-14.00 (13.50); AR 1.00 (1). Frontal sclerite (Fig. $3 b)$ broad, somewhat oval in shape, with central hollow region, 28.00-30.00 (29.50) $\mu \mathrm{m}$ long and 19.50-21.00 (21.00) $\mu \mathrm{m}$ wide, not heavily sclerotised. Clypeus broad and tapering uniformly, with 4 pairs of setae. Maxillary palpus as in figure $3 \mathrm{c}$; length ratio of palpal segments (I-V): 2.00 (2.00): 5.00 (5.00): 8.00-9.00 (8.50): 5.00 (5.00): 6.00-6.50 (6.00); terminal palp segment V cylindrical with 4 setae; PR 2.25-2.50 (2.25).

Thorax. Light brown in colour.

Wing (Fig. 3d). WL 0.65-0.68 (0.68) mm, WW 0.23-0.25 (0.25) mm. Macrotrichia sparse on wing surface. Apical one-third of cell $r_{5}$ covered with macrotrichia; CR $0.40-0.42$ $(0.42)$.

Legs (Fig. 3e). Pale brown in colour. Fore, mid and hind femur with diffuse infuscation at in mid-section. Hind tibial comb (Fig. 3f) bearing 6 spines. Tarsomeres I-IV light in colour, V slightly darker. 


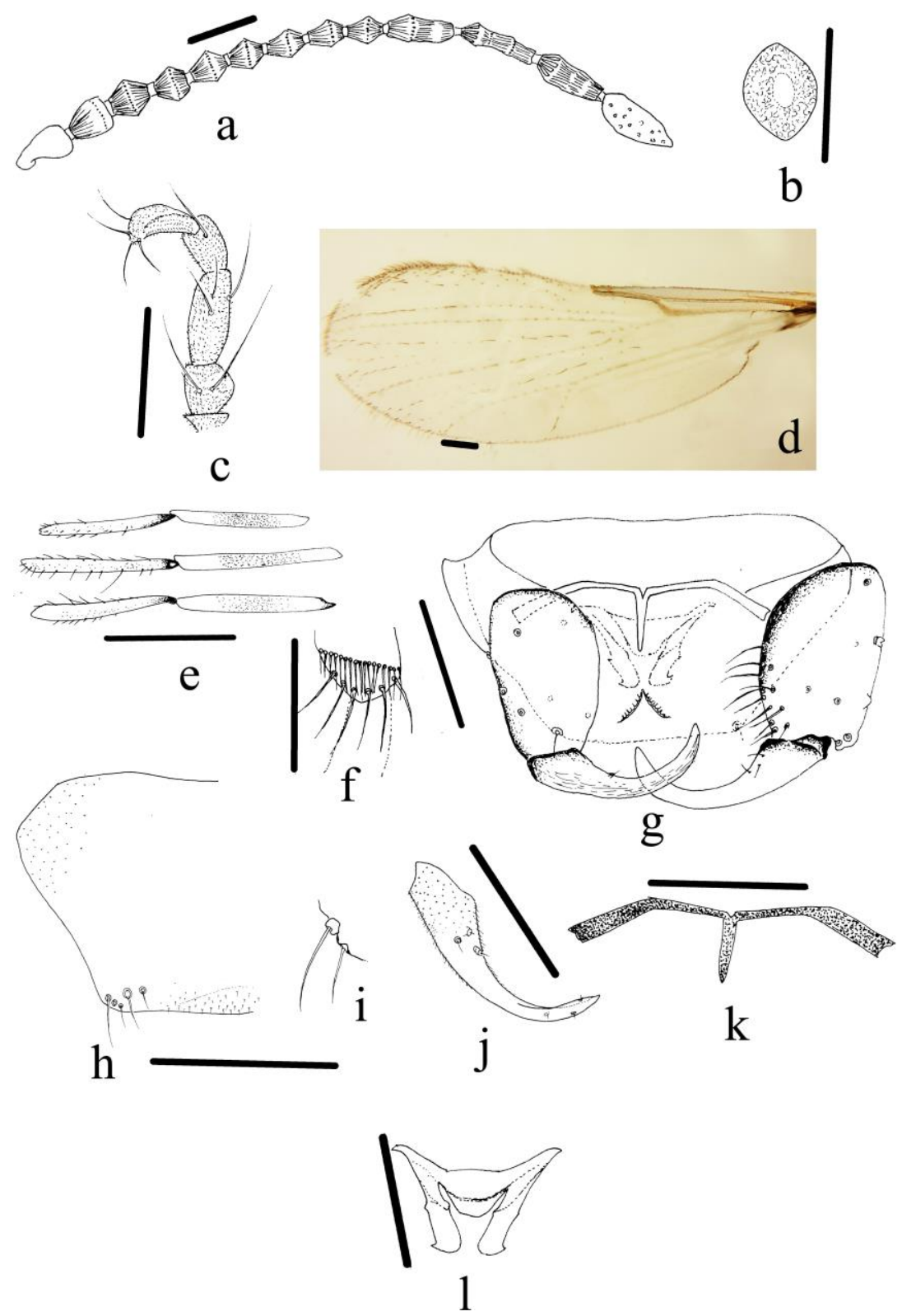

Fig. 3. Adult male of Dasyhelea (Sebessia) scalpra sp. n.: a, Flagellomeres; b, Frontal sclerite; c, Maxillary palp; d, Wing; e, Femora and tibiae of fore, mid and hind legs; f, Hind tibial comb; g, Genitalia showing left dorsal and right ventral view; h, tergite 9 showing the cercus (left half); i, Apicolateral process; j, Enlarged view of gonostylus; k, Paramere; 1, Aedeagus. Scale bar: $0.05 \mathrm{~mm}$. 
Abdomen. Tergites brown in colour.

Genitalia (Fig. 3g). Tergite 9 very broad in anterior region, posterior part half as wide as anterior, extended up to apex of gonocoxite, cercus (Fig. 3h) with 2 long setae and 3 short setae; apicolateral processes (Fig. 3i) minute with one longer and one shorter seta. Sternite 9 extended up to tip of posteromedial projection of aedeagus, $0.20 \times$ length of greatest width. Gonocoxite broad, stout, somewhat oval in shape, 52.50-54.00 (54.00) $\mu \mathrm{m}$ long, 27.50-30.00 (30.00) $\mu \mathrm{m}$ wide. Gonostylus (Fig. 3j) semi-circularly arched, 57.50 $60.00(60.00) \mu \mathrm{m}$ long, tip pointed. Paramere (Fig. 3k) symmetrical, basal arms slender, directed laterad; posteromedial arm stout, short, slender, blunt apex. Aedeagus (Fig. 31) "M"-shaped, $27.00 \mu \mathrm{m}$ long, with an arch of 31.50-33.00 (33.00) $\mu \mathrm{m}$, basal arms short, directed laterad, posterolateral arms stout, recurved laterally with a small projection in middle of arm. An inverted "V" shaped setose region present below aedeagus.

\section{Female}

Unknown.

\section{Immature}

Unknown.

\section{Remarks}

Dasyhelea scalpra sp. n. shares similarities with D. (Sebessia) saetula YU, 2005 and D. doratos YU, 2005 in the nearly similarly shaped arched gonostylus, very similar basal arms of the paramere and the aedeagus with curve-tipped posterolateral arms. In contrast, $D$. scalpra sp. $\mathrm{n}$. has a short, slender, blunt-tipped posteromedian projection of the paramere, posterolateral arms of the aedeagus with a small projection in the mid-section, and a domeshaped posteromedian projection of sternite 9. The combination of characters highlighted in the diagnosis justifies setting up D. (Sebessia) scalpra sp. n. as a new member of this genus.

\section{Etymology}

The name, 'scalpra', refers to the Latinised version of short, slender, blunt-tipped, knife-shaped posteromedian projection of the aedeagus of the male genitalia.

Distribution

India (West Bengal, altitude: 20-21 m). 


\section{Dasyhelea (Pseudoculicoides) deemingi BOORMAN \& HARTEN}

(Figs. 4a-h)

Dasyhelea deemingi BOORMAN \& HARTEN, 2002: 444

Dasyheleala binoda MAZUMDAR \& CHAUDHURI, 2009: 195;

DOMINIAK \& ALWIN, 2013: 137

\section{Material examined}

5 males, India, West Bengal, Nadia, Krishnanagar [232 $\left.23^{\prime} 55.5^{\prime \prime} \mathrm{N}, 88^{\circ} 29^{\prime} 33.7^{\prime \prime} \mathrm{E}\right]$, 02.X.2015, Coll. S. BRAHMA; 1 male, India, West Bengal, Birbhum, Ilambazar

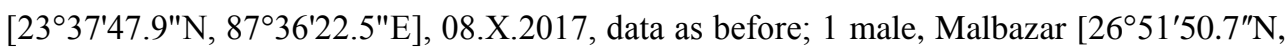
$\left.88^{\circ} 44^{\prime} 34^{\prime \prime} \mathrm{E}\right]$, 12.VII.2016, data as before; 1 male, India, West Bengal, Purba Bardhaman,

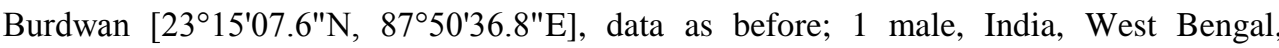

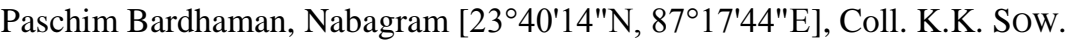

\section{Remarks}

The specimens collected during this study have been definitively identified as Dasyhelea deemingi BOORMAN \& HARTEN, 2002. D. deemingi was previously recorded from India by MAZUMDAR \& CHAUDHURI (2009). However, the original description and illustration of this species are insufficient for a complete diagnosis. Even the illustration in BOORMAN \& HARTEN (2002) is much too sketchy and their description is inadequate for a diagnosis. Our review reveals the following characteristics for a good diagnosis of the species. The frontal sclerite (Fig. 4a) is rhomboid with a posterior extension, the midsection is sclerotised, somewhat "kite"-shaped; the postscutellum yellowish brown in colour (Fig. 4b); the wing has macrotrichia on the anterior $r_{5}$ (Fig. 4c); tergite 9 (Fig. 4d) broad anteriorly, inverted trapezoidal, surpassing the gonocoxite, cercus setose with 2 long setae. The apex of the sternite 9 is $0.24 \times$ the length of the greatest width, and extends tongue-like up to the upper margin of the aedeagus (Fig. 4d). A number of additional characters of this species are also prominent in our study: tergite 9 bears a finger-like apicolateral process (Fig. 4e), has a setose cercus at the base and a distinct seta arising subapically; the gonostylus (Fig. 4f) has one prominent seta at about mid-length, and the apex bears two minute setae; the paramere (Fig. $4 \mathrm{~g}$ ) is highly asymmetrical, with the basal arms stout, broad, directed anterolaterad, the left one wave-like, the posteromedian projection heavily sclerotised with a short, distinct projection beyond mid-length; the basal arms of the aedeagus are spoon-like (Fig. 4h), the posterolateral arms exhibit a slight constriction in the subapical region, and the posteromedian projection is broad. 


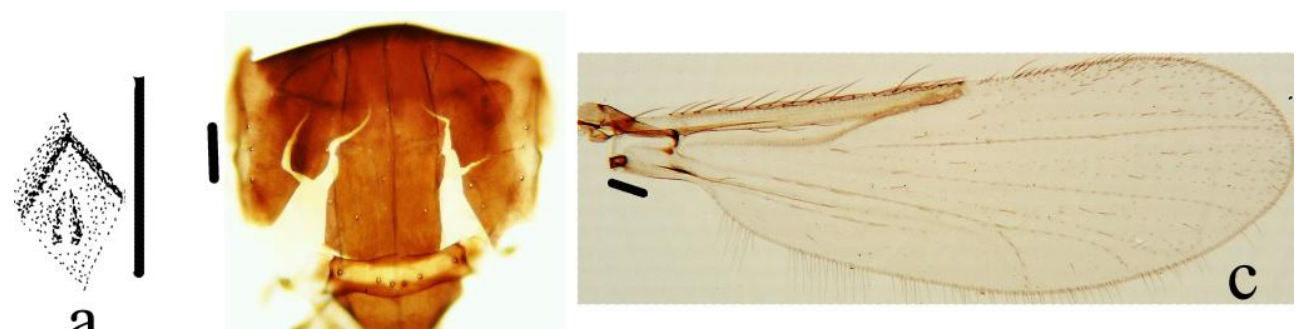

b
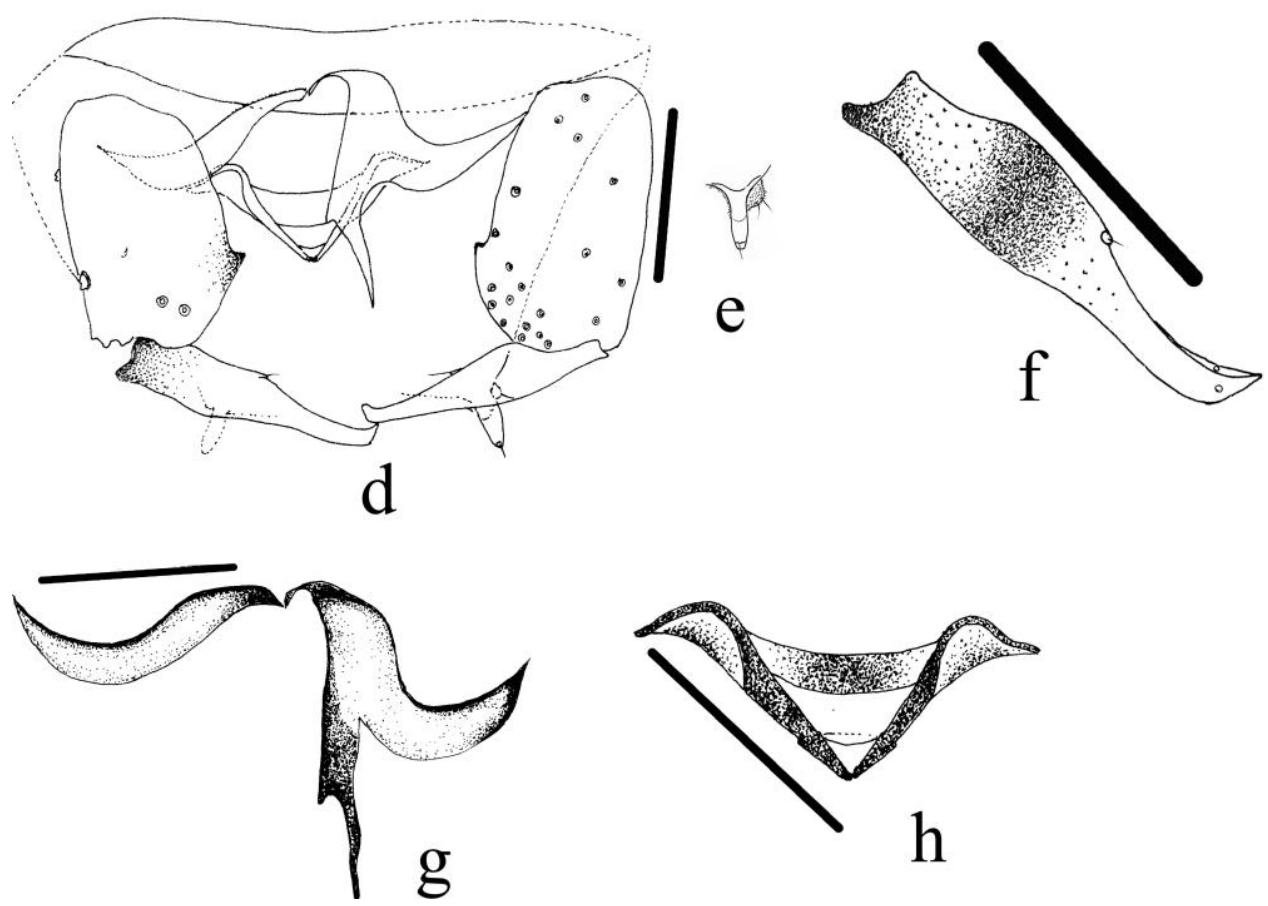

Fig. 4. Adult male of Dasyhelea (Pseudoculicoides) deemingi BOORMAN \& HARTEN, 2002: a, Frontal sclerite; b, Thorax; c, Wing; d, Genitalia showing left dorsal and right ventral view; e, Apicolateral process; f, Enlarged view of gonostylus; g, Paramere; h, Aedeagus. Scale bar: $0.05 \mathrm{~mm}$.

\section{Distribution}

Dasyhelea deemingi BOORMAN \& HARTEN, 2002 was previously recorded from Bahrain, Oman, UAE and Saudi Arabia. MAZUMDAR \& CHAUdHURI (2009) described it from India - this was the first record from the Oriental Region. 


\section{Dasyhelea (Pseudoculicoides) similinigrina NAVAI, 1994}

Dasyhelea (Pseudoculicoides) acuta BrAHMA, SAHA \& HAZRA, 2016: 237. Syn. Nov.

\section{Material examined}

1 male, India, West Bengal, Nadia, Krishnanagar [232 $23^{\prime} 56.0^{\prime \prime} \mathrm{N}, 88^{\circ} 29^{\prime} 50.9^{\prime \prime} \mathrm{E}$ ], 21.II.2017, Coll. S. BRAHMA; 1 male, India, West Bengal, Birbhum, Shikaripara [2414'27.8"N 8741'17.4"E], 24.II.2017, Coll. S. ChatTerJeE; 3 males, India, West

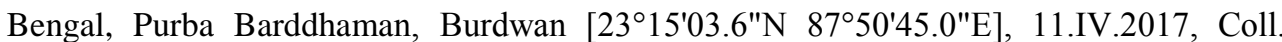
BRAHMA; 1 male, India, West Bengal, Coochbehar, Bhetaguri [26 $12^{\prime} 05.0^{\prime \prime} \mathrm{N}$ 89²8'54.0"E], 22.X.2011, Coll. S. BRAHMA.

\section{Distribution}

To date D. (Pseudoculicoides) similinigrina NAVAI, 1994 has been recorded in Afghanistan, China (YU et al., 2005) and India (BRAHMA et al. 2016).

\section{Remarks}

After careful study of more specimens of Dasyhelea acuta, we consider Dasyhelea acuta and D. similinigrina to be conspecific. The incorrect mounting of the genitalia resulted in important diagnostic characters being overlooked; hence, the dilemma. Currently, we propose to treat $D$. acuta as a junior synonym of $D$. similinigrina. New synonymy.

\section{Dasyhelea (Pseudoculicoides) comosa BRAHMA, SAHA \& HAZRA, 2016}

(Figs 5a-b)

\section{Material examined}

Holotype male, labelled 'Dasyhelea (Pseudoculicoides) comosa BRAHMA, SAHA

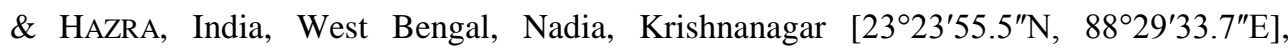
08.X.2015'; 2 males, 02.X.2015, data as holotype. 1 male, India, West Bengal, Jalpaiguri, Malbazar [2651'50.7"N, 8844'34"E], 12.VII.2016, Coll. S. BRAHMA.

\section{Remarks}

The adult male genitalia have been redrawn (Fig. 5a) following the correction of the illustration of the paramere (Fig. 5b). The posteromedian projection of the paramere consists of a prominent, long projection at the base, a good diagnostic character. 

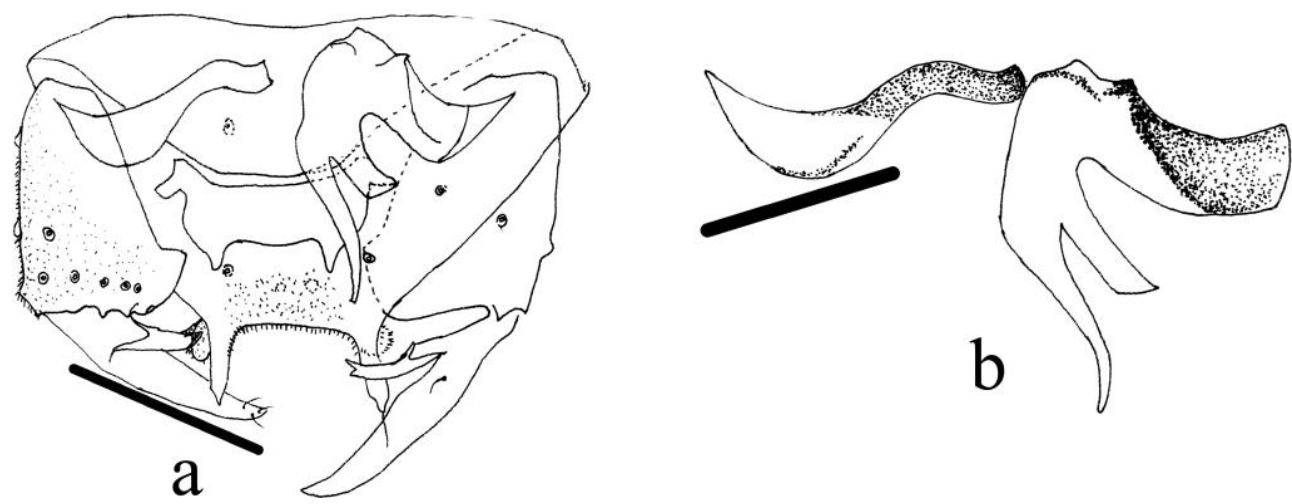

Fig. 5. Adult male of Dasyhelea (Pseudoculicoides) comosa BRAHMA, SAHA \& HAZRA, 2016. A, Genitalia showing left dorsal and right ventral view; b, Paramere. Scale bar: 0.05 $\mathrm{mm}$.

\section{Subgenus Dasyhelea KIEFFER, 1911 \\ Dasyhelea (Dasyhelea) pallidiventris GOETGHEBUER, 1931}

(Figs. 6a-j)

Dasyhelea olivacea REMM, 1962: 117

Dasyhelea versicolor REMM, 1979: 50

\section{Material examined}

3 males, India, West Bengal, Nadia, Krishnanagar [232 $\left.3^{\prime} 56.0^{\prime \prime} \mathrm{N}, 8^{\circ} 29^{\prime} 50.9^{\prime \prime} \mathrm{E}\right]$, 21.II.2017, Coll. S. BRAHMA.

\section{Remarks}

This species is very similar to Dasyhelea (Dasyhelea) pallidiventris GOETGHEBUER, 1931 except for a few morphological differences like the apex of the aedeagus, the setal arrangement on the dorsal side of the gonocoxite, and the number of setae distad of the gonostylus. 


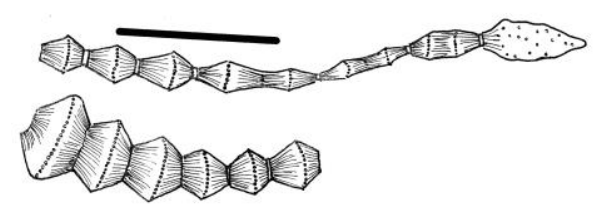

a

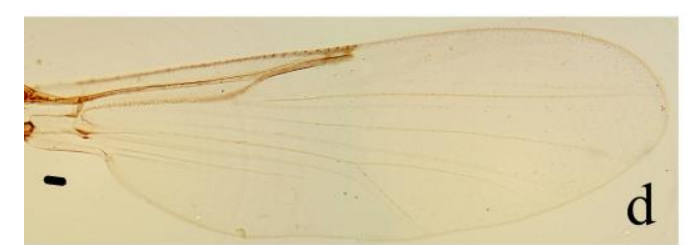

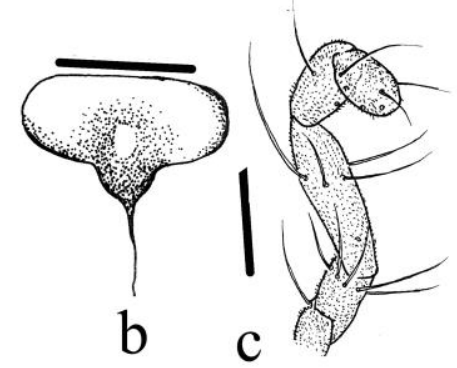
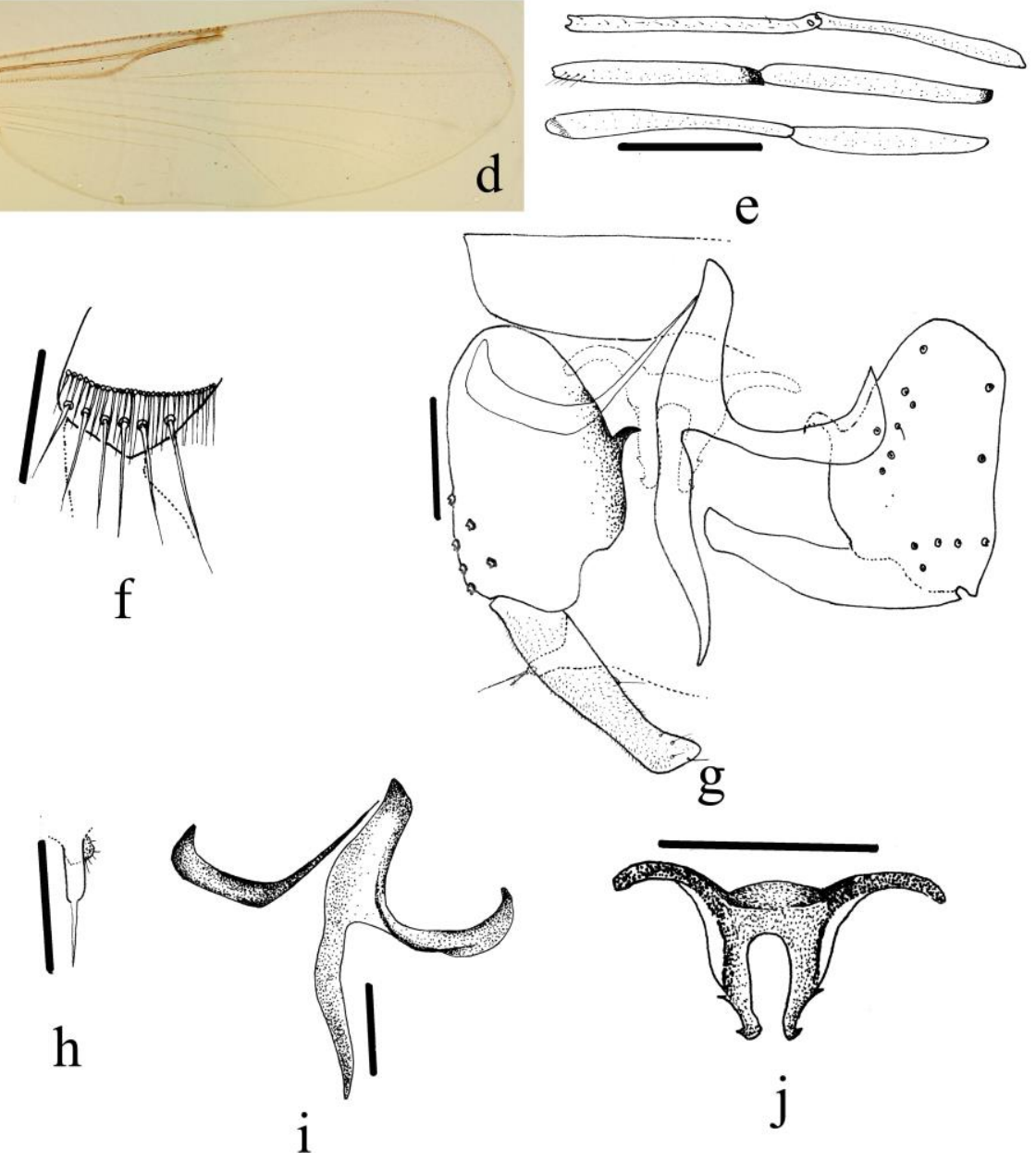

Fig. 6. Adult male of Dasyhelea (Dasyhelea) pallidiventris GOETGHEBUER, 1931: a, Flagellomeres; b, Frontal sclerite; c, Maxillary palp; d, Wing; e, Femora and tibiae of fore, mid and hind legs; f, Hind tibial comb; g, Genitalia showing left dorsal and right ventral view; h, Apicolateral process; i, Parameres; j, Aedeagus. Scale bar: 0.05 mm. 


\section{Distribution}

Dasyhelea (Dasyhelea) pallidiventris GOETGHEBUER, 1931 was previously recorded from the Palaearctic Region, i.e. Poland (SZADZIEWSKI 1983, 1986, DOMINIAK \& SZADZIEWSKI 2006, GWIZDALSKA-KenTZER 2011), the Czech Republic (TÓTHOVÁ et al. 2004), Finland and North Korea (REMM 1979), Estonia (REMM 1962), Lithuania (REMM 1966), Azerbaijan and Georgia (Remm 1967) and Ukraine (REMm \& ZHOGOLEv 1968). This is the first report of this species from the Oriental Region.

\section{KEY TO THE INDIAN MALE SPECIES OF SUBGENERA DASYHELEA S.STR., PROKEMPIA, PSEUDOCULICOIDES AND SEBESSIA}

1. Gonocoxite with mesoventral hook. Subgenus Dasyhelea KIEFFER, 1911 s. str. D. (Dasyhelea) pallidiventris GOETGHEBUER, 1931

- Gonocoxite with no mesoventral hook. 2

2. Posterior margin of sternite 9 extended downwards, without any pincer-like median process; apicolateral process prominent.

- Posterior margin of sternite 9 rounded or with a pincer-like median process; apicolateral process minute or prominent.

3. Paramere symmetrical, posterior margin of sternite 9 covering entire aedeagus; posterolateral arm of aedeagus with a small projection at mid-length, simple; gonostylus arched semi-circularly; posteromedian projection of paramere slender, knife-shaped and equally connected with both apodemal halves. Subgenus Sebessia REMM, 1979 D. (Sebessia) scalpra $\mathbf{~ s p . ~} \mathbf{n}$.

- Paramere asymmetrical, posterior margin of sternite 9 not covering aedeagus; posterolateral arm of aedeagus with no small projection at mid-length, simple or bifurcate; gonostylus straight or slightly curved; posteromedian projection of paramere very long, tubular, curved, unequally connected with both apodemal halves.

Subgenus Prokempia KIEFFER, 1913

4. Gonostylus bifurcate, outer gonostylus with a distinct stout seta at about mid-length, inner one having a distinct seta beyond mid-length, without any constriction or setose margin. D. (Prokempia) flava CARTER, INGRAM \& MACFIE, 1921

- Gonostylus simple, basal region with 3 prominent long setae, proximal one-third region with a prominent constriction and setose boundary. ..... D. (Prokempia) barbistyla sp.n.

5. Gonostylus simple.

- Gonostylus forked. 
6. Gonocoxite with inner notch beyond mid-length; a prominent seta at about mid-length of inner side of gonostylus; posteromedian projection of paramere with a distinct projection beyond mid-length; basal arms of aedeagus spoon-like, posterolateral arms not twisted, straight, curved at tip. D. (Ps.) deemingi BOORMAN \&HARTEN, 2002

- Gonocoxite without inner notch; seta absent at about mid-length of inner side of gonostylus; no projection in posteromedian arm of paramere; basal arms of aedeagus not spoon-like, posterolateral arms twisted, curved at tip.

D. (Ps.) similinigrina NAVAI, 1994

7. Inner gonostylus with additional bifurcation at apex; right half of paramere with a distinct projection, posteromedian projection missing "heel"-like apex; base of apicolateral process with a long, distinct seta.

D. (Ps.) comosa BRAHMA, SAHA \& HAZRA, 2016

- Inner gonostylus without any bifurcation at apex; right half of paramere devoid of any distinct projection, posteromedian projection terminating in "heel"-like apex; base of apicolateral process without any distinct seta. D. (Ps.) pseudohama sp. n.

\section{ACKNOWLEDGEMENTS}

We are grateful to Dr P.K. ChaUdHURI, Former Professor, Department of Zoology, The University of Burdwan, for kindly going through the manuscript and making helpful suggestions. The authors express their sincere thanks to Mr. Basudev DAS, Senior Technical Assistant, University Science Instrumentation Centre (USIC), University of Burdwan, for producing and maintaining the ultraviolet light traps. The authors thank the Head, Department of Zoology The University of Burdwan, for placing infrastructure at our disposal. Thanks are due to the Department of Forest, Government of West Bengal, for allowing us to carry out the fieldwork.

The research was supported by the West Bengal Biodiversity Board, Govt. of West Bengal (No. 703/ 3K(Bio)-1/2016).

\section{REFERENCES}

BoORMAn J., van Harten A. 2002. Some Ceratopogonidae (Insecta: Diptera) from the Arabian Peninsula, with particular reference to the Republic of Yemen. Fauna of Arabia, 19: 427-462.

BoRKENT A. 2016. World Species of Biting Midges (Diptera: Ceratopogonidae). Internet: http://www.inhs.uiuc.edu/cee/FLYTREE/Ceratopogonidae Catalog.pdf (Accessed 19 Sept. 2017) 
Brahma S., Saha P., Hazra N. 2016. Two new species and new records of biting midges of the genus Dasyhelea KIEFFER (Diptera: Ceratopogonidae) from India. Annales de la Société Entomologique de France N.S., 52 (4): 233-242.

Brown B.V., Borkent A., Cumming J.M., Wood D.M., Woodley N.E., Zumbado M.A. 2009. Manual of Central American Diptera. Volume 1, NRC Research Press, Ottawa, Ontario, Canada.

CARTER H.F., INGRAm A., MACFIE J.W.S. 1921. Observations on the ceratopogonine midges of the Gold Coast with descriptions of new species Part IV. Annals of Tropical Medicine and Parasitology, 15 (3): 177-212.

DOMNIAK P. 2012. Biting midges of the genus Dasyhelea KIEFFER (Diptera: Ceratopogonidae) in Poland. Polish Journal of Entomology, 81 (3): 211-304.

DominiaK P., Alwin A. 2013. Five new species and new records of biting midges of the genus Dasyhelea KIEFFER from the Near East (Diptera: Ceratopogonidae). Zootaxa, 3683: 133-144.

Dominiak P., SZADZiewski R. 2006. Biting midges of the genus Dasyhelea KiEFFER, 1911 (Diptera: Ceratopogonidae) collected from Polish peat-bogs. Dipteron, 22: 4-7. [in Polish, with English abstract]

Goetghebuer M. 1931. Ceratopogonidae et Chironomidae nouveaux d'Europe. Bulletin et Annales de la Société Entomologique de Belgique, 71: 211-218.

Grogan W.L., WiEners J.A. 2006. A new species of the biting midge genus Dasyhelea KIEFFER (Diptera: Ceratopogonidae) from the Bahamas. Proceedings of the Entomological Society of Washington, 108 (2): 467-473.

Gwizdalska-KentZer M. 2011. Biting midges (Diptera: Ceratopogonidae) of the Łęg nad Swelinią reserve. Dipteron, 27: 32-39 [in Polish, with English abstract]

KIEFFER J.J. 1911. Nouvelles descriptions de chironomides obtenus d'éclosion. Bulletin de la Société d'Histoire Naturelle de Moselle, 27: 1-60.

KIEFFER J.J. 1913. Nouvelle étude sur les chironomides de l'Indian Museum de Calcutta. Records of the Indian Museum, 9: 119-197, pls. 11-12.

KIEFFER J.J. 1915. Neue Chironomiden aus Mitteleuropa. Brotéria Serie Zoologica, 13: 65-87.

KIEFFER J.J. 1925. 16. Chironomiden der Hochmoore Nordeuropas und des östlichen Mitteleuropas. Beiträge zur Kunde Estlands, 10: 145-163.

LATREILLE P.A. 1809. Genera crustaceorum et insectorum secundum ordinem naturalem in familias disposita, iconibus exemplisque plurimis explicata. Tomus quartus et ultimus. König, Paris and Strasbourg.

MaLlOCH J.R. 1915. The Chironomidae, or midges, of Illinois, with particular reference to the species occurring in the Illinois river. Bulletin of the Illinois State Laboratory of Natural History, 10: $275-543,24$ pls.

Mazumdar A., Chaudhuri P.K. 2009. Indian species of the genus Dasyhelea KIEFFER (Diptera: Ceratopogonidae). International Journal of Dipterological Research, 20: 191-201.

MEIGEN J.W. 1818. Systematische Beschreibung der bekannten europäischen zweiflügeligen Insekten. Band 1. Beaufort Sohn, Aachen.

Navai S. 1994. Biting midges of the genus Dasyhelea from Afghanistan, with descriptions of new species (Diptera, Ceratopogonidae). Deutsche Entomologische Zeitschrift, 41 (2): 357-399. 
REMm H. 1962. The genus Dasyhelea KIEFFER in Estonia (Diptera, Heleidae). Tartu Riikliku Ülikooli Toimetised, 120: 108-133. [in Russian, with English summary]

Remm H. 1966. On the Lithuanian biting midges (Diptera, Heleidae). Tartu Riikliku Ülikooli Toimetised, 180: 53-71. [in Russian, with English summary]

REMm H. 1967. On the fauna of Ceratopogonidae (Diptera) in the Caucasus. Tartu Riikliku Ülikooli Toimetised, 194: 3-37. [in Russian, with English summary]

Remm H. 1972. New species of Ceratopogonidae (Diptera) from the south Siberia. Tartu Riikliku Ülikooli Toimetised, 293: 62-90. [in Russian, with English summary]

Remm H. 1979. A catalogue of the Ceratopogonidae (Diptera) of the Estonian S.S.R. Eesti NSV Teaduste Akadeemia, Tartu. [in Estonian, with Russian and English summaries]

Remm H., Zhogolev D.T. 1968. Contributions to the fauna of biting-midges (Diptera, Ceratopogonidae) of the Crimea. Entomologičeskoe Obozrenie, 47: 826-842. [in Russian, with English summary]

SzADZIEwSKI R. 1983. Flies (Diptera) of the saline habitats of Poland. Polish Journal of Entomology, 53 (1): 31-76.

SzADZIEWSKI R. 1986. Redescriptions and notes on some Ceratopogonidae (Diptera). Polish Journal of Entomology, 56 (1): 3-103.

ToKUnAGa M. 1940. Biting midges from Japan and neighbouring countries, including Micronesian Islands, Manchuria, North China and Mongolia (Diptera, Ceratopogonidae). Tenthredo, 3: $101-165$.

Tóthová A., BARTÁK M., KNOZ J. 2004. Ceratopogonidae of Southern Moravia (NP Podyjí). [in:] P. BITUŠIK (ed.). Dipterologica Bohemoslovaca 12. Acta Facultatis Ecologiae, 12, supl 1: 143-148.

Wang F., Huang E., Zhang L.L., Yu Y., Guan X., OuYang M.A. 2015. Two new species of the genus Dasyhelea KIEFFER (Diptera: Ceratopogonidae) from China. Oriental Insects, 48 (3): 312-315.

Wirth W.W., Marston N. 1968. A method for mounting small insects on microscopic slides in Canada balsam. Annals of the Entomological Society of America, 61 (3): 783-784.

YU Y.X. 2003. A new species of the genus Dasyhelea Kieffer (Diptera: Ceratopogonidae) from Vietnam. Acta Entomologica Sinica, 10 (1): 69-71.

YU Y.X. 2005. Subfamily Dasyheleinae Lenz, Genus Dasyhelea KIEFFER, 1911. [in:] Y.X. YU, J.H. LiU, G.P. LiU, Z.J. LiU, B.S. HAO, G. YAN, T.S. ZhaO (eds). Ceratopogonidae of China, Insecta, Diptera (Vol. 1). Military Medical Science Press, Beijing, China, 115-326. [in Chinese]

Received: 16 March 2018

Accepted: 16 August 2018 